\title{
Competitive hierarchies among three species of juvenile coral reef fishes
}

\author{
Shane W. Geange ${ }^{1, *}$, Adrian C. Stier ${ }^{2}$, Jeffrey S. Shima ${ }^{1}$ \\ ${ }^{1}$ School of Biological Sciences, Victoria University of Wellington, PO Box 600, Wellington 6023, New Zealand \\ ${ }^{2}$ Department of Biology, University of Florida, Gainesville, Florida 32611-8525, USA
}

\begin{abstract}
Interspecific competition is often asymmetric, and it can limit the spatial distributions of competitively inferior species within a community. When asymmetric competition involves 2 or more component species, the ranking of species' competitive abilities may form competitive hierarchies (all species of higher rank out-compete all species of lower rank) or competitive networks (at least 1 species of lower rank out-competes $\geq 1$ species of higher rank). Expectations of resource monopolization and patterns of distribution and abundance among species in competitive networks are expected to differ from those in competitive hierarchies. We conducted a field experiment to evaluate the relative competitive abilities of juveniles of 3 closely related species of reef fish (bird wrasse Gomphosus varius, fivestripe wrasse Thalassoma quinquevittatum and the sixbar wrasse T. hardwicke) on Moorea, French Polynesia. We controlled for intrinsic variation in survivorship among species and found that competition among these 3 species was highly asymmetric, resulting in a simple competitive hierarchy (sequence of competitive ability from superior to inferior competitors): fivestripe wrasse $>$ bird wrasse $>$ sixbar wrasse. We surveyed densities of the 3 reef fish species on 55 patch reefs and observed significant negative spatial covariation between superior and inferior competitors, consistent with competitive hierarchies that limit the spatial distributions of the inferior species (sixbar wrasse). Our work demonstrates that intense asymmetric competition and the formation of competitive hierarchies may be an important determinant of resource monopolization and patterns of distribution and abundance in reef fishes.
\end{abstract}

KEY WORDS: Asymmetric competition - Competitive hierarchies - Interspecific interactions · Wrasse $\cdot$ Gomphosus $\cdot$ Thalassoma $\cdot$ French Polynesia

\section{INTRODUCTION}

Interspecific competition can be intense in natural communities and is often an important determinant of resource monopolization as well as patterns of distribution and abundance (e.g. Connell 1961, Gladfelter et al. 1980, Anderson et al. 1981, Schmitt \& Holbrook 1990, Robertson 1996, Munday et al. 2001, Munday 2004). Interspecific competition between 2 species can be symmetric (i.e. species are competitively interchangeable; sp. A = sp. B), with species coexistence determined by priority of arrival of recruits (e.g. Munday 2004, Geange \& Stier 2009).
Alternatively, interspecific competition may be asymmetric (i.e. superior competitors dominate a larger portion of the resource, excluding inferior competitors; sp. A > sp. B), with inferior competitors persisting in the system via a range of mechanisms, including competition-colonization tradeoffs (Levins \& Culver 1971, Tilman 1994, Hurtt \& Pacala 1995), disturbance (Connell 1978, Huston 1979, Tilman 1982) and aggregation in patchy habitats (Atkinson \& Shorrocks 1981, Hanski 1981).

When competition is asymmetric, a common hypothesis is that, all else being equal, superior competitors exclude inferior competitors (e.g. Hardin 1960), 
resulting in negative spatial (or temporal) covariation in the distribution of each competitor (Colwell \& Fuentes 1975, Connell 1983, Schoener 1983, Munday et al. 2001, Young 2004). However, when pairs of inferior and superior competitors are embedded within a suite of competing species, the outcome of competition and influences on species distributions may be altered. For example, when relative competitive abilities take the form of competitive networks, in which a loop in an otherwise hierarchical sequence of competitive abilities occurs (e.g. sp. A > sp. B, sp. B > sp. C, but sp. C > sp. A), the presence of intransitives may stabilize coexistence (i.e. addition of species may disrupt expectations of negative spatial co-variation between the original 2 species because a lower ranked competitor can out-compete $\geq 1$ higher ranked competitors) (Buss \& Jackson 1979, Levine 1999, Allesina \& Levine 2011). Competitive networks can lead to indefinite coexistence of the 3 species (Laird \& Schamp 2006, Reichenbach et al. 2007) and facilitate the coexistence of many more species with appropriate resource-consumer interactions (Huisman et al. 2001). Conversely, relative competitive abilities can take the form of hierarchical sequences in which all competitors of a higher rank out-compete all competitors of a lower rank (e.g. sp. A > sp. B, sp. B > sp. C and sp. A > sp. C). In this scenario, patterns of negative spatial co-variation between pairs of inferior and superior competitors should be maintained (or amplified) when embedded within suites of competing species. We therefore expect a single winner, with the best competitor driving all others extinct unless some other mechanism facilitates coexistence.

In reef fishes, competitive interactions have historically been considered more or less symmetric, with species coexistence determined by a number of mechanisms, including priority of arrival (Sale 1974, 1976, 1977, 1978, 1980, Talbot et al. 1978) or storage effects (Chesson \& Warner 1981, Chesson 1994, 2000). Over the last few decades, it has become clear that competition is often asymmetric and can influence the distribution and abundance of reef fishes (e.g. Hixon 1980, Larson 1980, Ebersole 1985, Schmitt \& Holbrook 1990, 1999, Holbrook \& Schmitt 1995, Robertson 1996, Munday 2004). Although competition in reef fishes may occur among suites of species, rankings of relative competitive abilities and documentation of competitive networks or competitive hierarchies are rare. Juvenile reef fishes provide an exciting opportunity to examine relative competitive abilities because few studies have examined the role and importance of competition among recently set- tled reef fishes at this important life-history boundary, and because those few studies focused primarily on pairs of competitive species. As individuals make the transition from a pelagic environment (where they develop as larvae) to benthic reef habitat, they encounter multiple fish species with highly similar resource requirements. Consequently, interference competition for habitat resources among suites of juvenile reef fish species is commonplace (e.g. Munday et al. 2001, Almany 2003), and such interactions may determine the success of newly arrived individuals, e.g. if superior competitors exclude inferior competitors from mutually preferred habitats (Robertson \& Gaines 1986, Munday et al. 2001, Geange 2010) and increase their exposure to predators (Holbrook \& Schmitt 2002). Ultimately, a pattern of negative spatial co-variation between superior and inferior competitors may ensue, with important demographic consequences for subsequent life-history stages.

Here, we conduct a field experiment to determine whether competitive interactions are symmetric or asymmetric for 3 species of juvenile coral reef fishes. Our experiments facilitate estimates of relative competitive abilities for all pairwise combinations and the placement of pairs of competitors within a 3-species suite of competitors. This enables us to evaluate whether competitive interactions take the form of a competitive network or a competitive hierarchy. We compare the results of our experiments with surveys of reef fish density to evaluate whether our expectations of competitive interactions (based upon the experiments) match our observations of spatial covariation among these 3 species of reef fish.

\section{MATERIALS AND METHODS}

\section{Study system}

We conducted the study in the northern lagoon of Moorea, French Polynesia $\left(17^{\circ} 30^{\prime} \mathrm{S}, 149^{\circ} 50^{\prime} \mathrm{W}\right)$. The northern lagoon is $\sim 800$ to $\sim 900 \mathrm{~m}$ wide, as measured from the shore to the reef crest, and is interspersed with patch reefs separated from one another by a mixture of sand, fine coral rubble and coral pavement (Galzin \& Pointer 1985). Patch reefs are predominantly Porites spp., often surmounted by smaller colonies of branching corals, dead coral skeletons, patches of macroalgae or lush stands of filamentous algae. The focal reef fishes in our study are closely related wrasses (Family Labridae: bird wrasse Gom- 
phosus varius, fivestripe wrasse Thalassoma quinquevittatum and sixbar wrasse T. hardwicke) that cooccur on reefs throughout the Indo-Pacific (Myers 1999). Collectively, these 3 species constitute nearly $70 \%$ of all juvenile labrids within the northern lagoon of Moorea (S. W. Geange unpubl. data). After an approximately 39 to 68 d planktonic larval duration (Victor 1986), these species settle in pulses around the new moon at a standard length (SL) of 9 to $11 \mathrm{~mm}$, forming mixed species groups in which multiple species frequently come into contact with each other (S. W. Geange pers. obs.). At our study site, juveniles of all 3 species use similar habitats; all 3 species form strong associations with massive Porites corals and Pocillopora verrucosa (Geange 2010). All 3 species also have similar diets, feeding predominantly on planktonic and benthic crustaceans (Randall 2005). Interference competition between species (presumably for habitat) generally consists of chases and fin bites, and such agonistic interactions are common (Geange \& Stier 2009).

\section{Experimental test of competitive asymmetry}

We constructed an array of 30 live-coral patch reefs and used these to conduct a field experiment that examined competitive asymmetry between bird wrasse, fivestripe wrasse and sixbar wrasse. On our constructed reefs, we aimed to minimize habitat variation by standardizing the reefs' size, rugosity and water depth. To achieve this, we selected natural reefs (based upon a set of morphological attributes that included a base of live Porites lobata coral with a surface area [mean $\pm \mathrm{SD}$ ] of $2.23 \pm 0.56 \mathrm{~m}^{2}$, and a height of $0.59 \pm 0.10 \mathrm{~m}$ ) from a nearby location and transplanted them to our study site $\left(17^{\circ} 29.010^{\prime} \mathrm{S}\right.$, $\left.149^{\circ} 50.346^{\prime} \mathrm{W}\right)$, an open sand flat 2 to $4 \mathrm{~m}$ deep. Each reef was separated from its nearest neighbor and other non-experimental reefs by a minimum of $10 \mathrm{~m}$. To each reef we attached 3 similar-sized colonies (colony surface area $=0.2 \pm 0.07 \mathrm{~m}^{2}$ ) of the branching coral Pocillopora verrucosa, which is representative of observed $P$. verrucosa cover within the lagoon (Shima et al. 2008), using Z-Spar Splash Zone Compound (Kopcoat).

Prior to starting the experiment, we removed all bird wrasse, fivestripe wrasse and sixbar wrasse from the reefs and manipulated the relative abundances of other resident fish species via selective removals and additions so that the relative abundance of all species was similar among the 30 reefs (see Supplement 1 at www.int-res.com/articles/suppl/m472p239_ supp.pdf for background community structure). We used the fish anesthetic eugenol (clove oil) and hand nets to collect fish.

We conducted pairwise comparisons of competitive asymmetry between bird wrasse, fivestripe wrasse and sixbar wrasse. To each reef, we randomly assigned 1 of 6 treatments: (1) 6 bird wrasses; (2) 6 fivestripe wrasses; (3) 6 sixbar wrasses; (4) 3 bird wrasses and 3 fivestripe wrasses; (5) 3 bird wrasses and 3 sixbar wrasses; or (6) 3 fivestripe wrasses and 3 sixbar wrasses. The densities used in this experiment $\left(\sim 2.6\right.$ ind. $\left.\mathrm{m}^{-2}\right)$ were equivalent to the maximum densities of sixbar wrasse observed by Shima (2001). Treatments 1 to 3 were used to assess speciesspecific survival in the absence of competitors. In these treatments, 3 'focal' individuals were randomly chosen a priori, and these individuals were used to estimate survivorship. Competitive asymmetry was assessed in Treatments 4 to 6 as differences in the fraction (over a fixed time interval) of survival of each species, standardized by species-specific survival in the absence of competitors (see Eq. 1). We ran the experiment in 2 temporal blocks (21 to 25 May 2008 and 2 to 6 June 2008), yielding 10 replicates for each of the 6 treatments, with treatments randomly assigned in each temporal block.

We used fish captured from reefs adjacent to the reef crest, $\sim 2 \mathrm{~km}$ from the study site. All captured fish were held in aquaria with running seawater for $24 \mathrm{~h}$ and then individually tagged with Visible Implant Elastomer (VIE; Northwest Marine Technology) anterior to the caudal peduncle. Different colors of VIE tags were used for each species. VIE tags were readable through the skin of the fish by observers in the field, so it was not necessary to recapture individuals to determine their identity. VIE tags do not have adverse effects on other fishes (Beukers et al. 1995, Imbert et al. 2007, Simon 2007) or on sixbar wrasse or fivestripe wrasse (Geange \& Stier 2009), and have been used to tag fish as small as $8 \mathrm{~mm}$ (Frederick 1997). We therefore assumed that tagging and handling effects were minimal and that these effects did not substantially differ among the 3 focal species. After tagging, we returned the fish to aerated aquaria for $24 \mathrm{~h}$ before measuring them to the nearest $0.1 \mathrm{~mm}$ SL. SL (mean $\pm \mathrm{SD}$ ) was $13.1 \pm 1.2 \mathrm{~mm}$ for bird wrasse, $13.1 \pm 1.4 \mathrm{~mm}$ for fivestripe wrasse and $12.7 \pm 1.3 \mathrm{~mm}$ for sixbar wrasse. For each experimental run, a 1-way analysis of variance indicated that SL of individuals at the time they were introduced to reefs did not statistically differ among species: $F_{2,177}=$ $0.669, \mathrm{p}=0.499$ and $F_{2,141}=2.864, \mathrm{p}=0.060$ for Expts 1 and 2, respectively. 
We surveyed reefs twice daily (approximately 08:00 and 16:00 h) for $5 \mathrm{~d}$ after the introduction of fishes. During surveys, we searched neighboring non-experimental reefs for tagged immigrants. We found no immigrants or emigrants. Previous research has shown that small reef fishes rarely move between reefs separated by as little as 15 m (Caselle 1999, Shima 2001), and previous studies on our experimental array found no migration of similar-sized fivestripe wrasse or sixbar wrasse (Geange \& Stier 2009, Geange \& Stier 2010). We therefore assume that the disappearance of an experimental fish was due to mortality rather than migration.

We used an analysis of variance to examine for a significant effect of the temporal blocks on the survival of focal species. Finding neither a significant interaction between temporal block and treatment ( $p=0.6997$ ) nor a significant main effect of temporal block ( $p=0.201$ ), we pooled temporal blocks and calculated means across all 10 replicates. Because survival in the absence of interspecific competitors was species-specific, we evaluated competitive symmetry using a standardized measure of competition incorporating species-specific survival. To achieve this, we defined a simple difference measure for the effect of species $j$ on the proportional survival of species $i$ :

$$
D_{i j}=\bar{P}_{i j}-\bar{A}_{i j}
$$

where $\bar{P}_{i j}$ is the mean proportional survival of species $i$ where species $j$ is present, $\bar{A}_{i j}$ is the mean proportional survival of species $i$ where species $j$ is absent, and $D_{i j}$ is the difference between these 2 means (the calculation of $D_{i j}$ is illustrated in Supplement 2 at www.int-res.com/articles/suppl/m472p239_ supp.pdf for a hypothetical dataset). The resulting standardized measures of competition range between -1 and 1 . A value of 0 indicates the per-capita effects of heterospecific competitors equaled those of conspecific competitors; negative values indicate the per-capita effects of heterospecific competitors were greater than those of conspecific competitors; positive values indicate the per-capita effects of conspecific competitors were greater than those of heterospecific competitors.

Tests for competitive effects

To test the null hypothesis that the presence of species $j$ did not affect the proportional survival of species $i$, we followed the approach of Gotelli et al. (2011). This approach allows the statistical compari- son of a single observation of $D_{i j}$ (with no associated error) against a distribution of simulated values for $D_{i j}$ that incorporate the variability within the raw data. For 1000 iterations, the values of the proportional survival of species $i$ were randomly reassigned to reefs with and without species $j$ (the randomization procedure is illustrated in Supplement 2). We then calculated a standardized effect size for the effect of species $j$ on species $i\left(\mathrm{SES}_{i j}\right)$ as follows:

$$
\mathrm{SES}_{i j}=\frac{D_{i j}-D_{i j(\operatorname{sim})}}{\sigma_{i j(\operatorname{sim})}}
$$

where $D_{i j}$ is the observed difference for species $i$ in the presence of species $j, D_{i j(\operatorname{sim})}$ is the mean difference in the simulated dataset, and $\sigma_{i j(s i m)}$ is the sample $\mathrm{SD}$ of the difference in the simulated dataset. This index quantifies the importance of species $j$ relative to the distribution of difference values in the randomized data (Gotelli et al. 2011). This measure of effect size is the number of SD units that the observed $D_{i j}$ lies above or below the expectation of the simulated distribution. If $\left|\mathrm{SES}_{i j}\right|>2$, then the observed value is approximately in the $5 \%$ tail of a normal distribution. If $\left|\mathrm{SES}_{i j}\right|<2$, the observed value is approximately within the range expected by chance at $\alpha=0.05$.

\section{Tests for competitive asymmetry}

To test the null hypothesis that competitive effects were symmetrical (i.e. $D_{i j}=D_{j i}$ ), we conducted a second analysis. We defined a difference matrix to test competitive asymmetry between species $i$ and $j\left(C A_{i j}\right)$ as follows:

$$
C A_{i j}=D_{j i}-D_{j i}
$$

Because we are interested in whether the magnitude of $D$ differs among focal species, we randomized the identity of focal species in reefs where competitors were absent and reefs where competitors were present (the randomization procedure is illustrated in Supplement 2 for a hypothetical dataset). We iterated this procedure 1000 times. We then calculated a standardized effect size for competitive asymmetry between species $i$ and $j\left(\operatorname{SES}_{i j}\right)$ as follows:

$$
C A_{\mathrm{SES}_{i j}}=\frac{C A_{i j}-C A_{i j(\operatorname{sim})}}{C A_{\sigma_{i j(\operatorname{sim})}}}
$$

where $C A_{i j}$ is the observed difference in $D$ for species $i$ and species $j, C A_{i j(\text { sim) }}$ is the mean difference in the simulated dataset, and $C A_{\sigma_{i j(s i m)}}$ is the sample SD of the difference in the simulated dataset. This index is a modification of that proposed by Gotelli et al. (2011) 
and quantifies the importance of competitive asymmetries relative to the distribution of difference values in the randomized data.

We conducted the 2 tests described above (for competitor effects and for competitive asymmetry) for each pairwise comparison between bird wrasse, fivestripe wrasse and sixbar wrasse. We implemented our randomizations in R 2.11.1 (R Development Core Team 2010).

\section{Competitive networks and competitive hierarchies}

Results of the analysis of competitive asymmetry were compiled into a contact matrix (e.g. Blower \& Mclean 1991) of all possible pairwise interactions among the 3 species. Examination of the contact matrix allowed determination of whether competitive interactions take the form of a competitive network or a competitive hierarchy.

\section{Expectations of spatial covariance among competing wrasses}

To determine the in situ spatial covariation of superior and inferior competitors, we surveyed the density of the 3 species at 3 locations (Teaharoa West: $17^{\circ} 28.397^{\prime} \mathrm{S}, 1^{\circ} 49^{\circ} 47.592^{\prime} \mathrm{W}_{\text {; }}$ Teaharoa East: $17^{\circ} 28.260^{\prime} \mathrm{S}, 149^{\circ} 47.118^{\prime} \mathrm{W}$; and Vaipahu: $\left.17^{\circ} 28.772^{\prime} \mathrm{S}, 149^{\circ} 50.879^{\prime} \mathrm{W}\right)$. Each location consisted of 2 sites that were arrayed perpendicular to the reef crest: a 'crest' site ( 95 m shoreward of the reef crest) and a 'lagoon' site ( 190 m shoreward of the reef crest). At each site, we haphazardly selected 16 patch reefs (hereafter reefs) of similar surface area (mean $\pm \mathrm{SD}$ ): $8.40 \pm 4.91 \mathrm{~m}^{2}$, and 8.23 $\pm 4.06 \mathrm{~m}^{2}$, for the crest and lagoon locations, respectively. On each reef and the surrounding $1 \mathrm{~m}$ halo, we counted juveniles of the 3 focal species, which we converted to densities. Juveniles were defined as individuals with SL $<25 \mathrm{~mm}$. Surveys were conducted between 08:00 and 16:00 h (peak activity time for diurnal benthic fishes) (Galzin 1987) from 27 May to 6 June 2005. As 41 of the 96 patch reefs surveyed were not inhabited by either bird wrasse, fivestripe wrasse or sixbar wrasse, we restricted the analysis to the 55 patch reefs upon which at least 1 of these species were counted.

To evaluate patterns in the density of inferior competitors as a function of the density of superior competitors, we fit linear and non-linear (negative exponential) models to our untransformed data. We chose the negative exponential because we expected constant changes in the density of superior competitors would result in the same proportional decrease in inferior competitors. We used Akaike's information criterion (AIC) to determine which model fit best. As differences in AIC scores between models were $<2$, indicating that both models fit the data equally well (after Burnham \& Anderson 1998), we present results from both models. All statistical analyses were conducted in R 2.11.1 (R Development Core Team 2010).

\section{RESULTS}

\section{Experimental test of competitive symmetry}

Mean $( \pm$ SD) survival in the absence of interspecific competitors was species-specific: $\bar{A}_{i j}$ was $0.52 \pm 0.12$ for bird wrasse, $0.21 \pm 0.15$ for fivestripe wrasse and $0.45 \pm 0.11$ for sixbar wrasse. In the presence of bird wrasse, mean survival $\bar{P}_{i j}$ was $0.42 \pm 0.21$ for fivestripe wrasse and $0.23 \pm 0.16$ for sixbar wrasse. Mean survival $\bar{P}_{i j}$ in the presence of fivestripe wrasse was $0.25 \pm 0.15$ for bird wrasse and $0.18 \pm 0.16$ for sixbar wrasse. In the presence of sixbar wrasse, mean survival $\bar{P}_{i j}$ was $0.53 \pm 0.28$ for bird wrasse and $0.67 \pm$ 0.16 for fivestripe wrasse. The difference in proportional survival between treatments where competitors were present or absent $(D)$ ranged between -0.278 (survival of sixbar wrasse in the presence of fivestripe wrasse) and 0.444 (survival of fivestripe wrasse in the presence of sixbar wrasse; Table 1, Fig. 1a).

Fivestripe wrasse versus sixbar wrasse

We identified competition between fivestripe wrasse and sixbar wrasse as being highly asymmetric (Fig. 2). The influence of competition with fivestripe wrasse on the local abundance of sixbar wrasse was significantly greater than the influence of competition with conspecifics (Table 1, Fig. 1a). For fivestripe wrasse, the influence of competition with sixbar wrasse on local abundance was less than the influence of competition with conspecifics (Table 1, Fig. 1a).

Bird wrasse versus fivestripe wrasse

Competition between bird wrasse and fivestripe wrasse was highly asymmetric (Fig. 2). For bird wrasse, competition with fivestripe wrasse had a statistically greater influence on local abundance than 
Table 1. Gomphosus varius, Thalassoma hardwicke, T. quinquevittatum. Difference metrics $(D)$ and corresponding standardized effect sizes (SES) obtained for 3 pairwise competitive interactions between bird wrasse, sixbar wrasse and fivestripe wrasse. Observed $D$ : magnitude and direction of competitive effects, negative values indicate that the percapita effect of heterospecific competitors was greater than that of conspecific competitors. SES > |2.0| (in bold) statistically significant competitive effects

\begin{tabular}{|llrr|}
\hline \multirow{2}{*}{ Species 1 } & Species 2 & Observed $D$ & \multicolumn{1}{c|}{ SES } \\
\hline Sixbar wrasse & & -0.278 & $\mathbf{- 2 . 9 3 6}$ \\
& Fivestripe wrasse & 0.444 & $\mathbf{3 . 3 7 0}$ \\
Bird wrasse & & -0.250 & $\mathbf{- 2 . 6 7 4}$ \\
& & 0.208 & 1.950 \\
Bird wrasse & & 0.017 & 0.147 \\
& Sixbar wrasse & -0.217 & $\mathbf{- 2 . 8 0 1}$ \\
\hline
\end{tabular}

competition with conspecifics (Table 1, Fig. 1b). Conversely, for fivestripe wrasse, the influence of competition with conspecifics on local abundance was statistically indistinguishable from the influence of competition with bird wrasse, although there was a trend for the influence of bird wrasse to be less than that of conspecifics (Table 1, Fig. 1b).

\section{Bird wrasse versus sixbar wrasse}

Although not statistically significant, competition between bird wrasse and sixbar wrasse tended to be

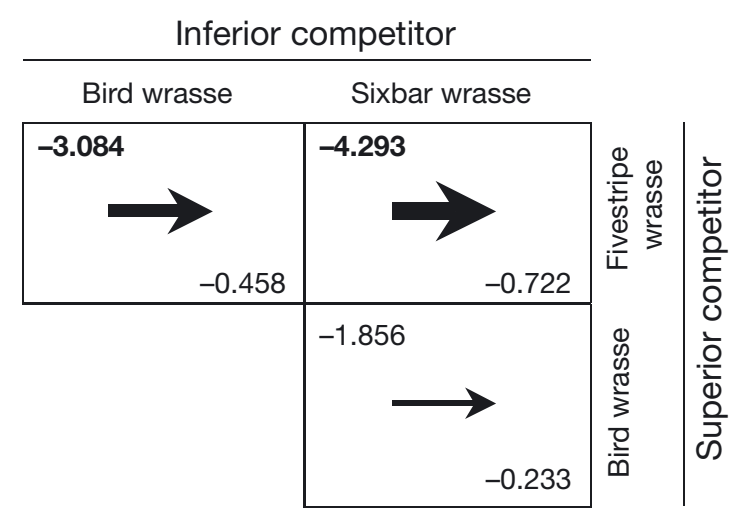

Fig. 2. Gomphosus varius, Thalassoma hardwicke, T. quinquevittatum. Contact matrix of pairwise competitive interactions between bird wrasse, sixbar wrasse and fivestripe wrasse. Arrows point in the direction of the superior competitor of each 2-species pair. Weight of the arrow = strength of competition. Top left corner of each cell: strength of the effect of superior competitors on inferior competitors (SES). Significant SES (> 2.0l) in bold. Bottom right corner: corresponding observed difference metric $(C A)$

asymmetric (Fig. 2). For bird wrasse, the influence of competition with conspecifics on local abundance was statistically indistinguishable from the influence of competition with sixbar wrasse (Fig. 1c, Table 1). Conversely, for sixbar wrasse, competition with bird wrasse had a statistically greater influence on local abundance than competition with conspecifics (Fig. 1c, Table 1).
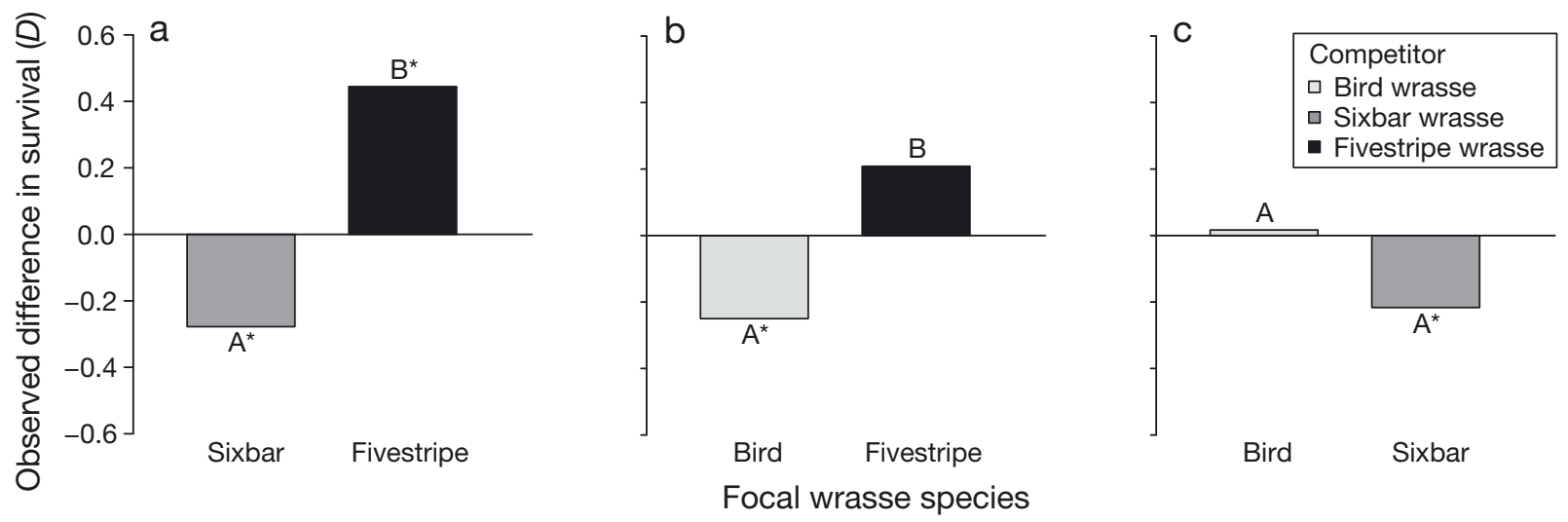

Fig. 1. Gomphosus varius, Thalassoma hardwicke, T. quinquevittatum. Pairwise patterns of competitive asymmetry between bird wrasse, sixbar wrasse and fivestripe wrasse, where $D$ is a simple difference measure for the per-capita effect of heterospecific competitors on the proportional survival of focal species (see 'Materials and methods'). Horizontal line at zero: per-capita effects of heterospecific competitors equal to that of conspecific competitors. Bars below the line: per-capita effects of heterospecific competitors were greater than the per-capita effects of conspecific competitors. Bars above the line: per-capita effects of conspecific competitors were greater than those of heterospecific competitors. Capital letters above means: statistically significant interspecific differences in $D$, as determined by SES (see Fig. 2), indicate competitive asymmetry. ${ }^{*}$ :statistically significant departures of $D$ from zero, as determined by standardized effect sizes (SES; see Table 1), indicates competitive effects 


\section{Competitive networks and competitive hierarchies}

Assessment of the contact matrix (Fig. 2) determined the presence of a competitive hierarchy, in which a simple linear sequence of competitive ability existed (arranged from superior to inferior competitor): fivestripe wrasse $>$ bird wrasse $>$ sixbar wrasse. The competition was greatest between fivestripe wrasse and sixbar wrasse, followed by fivestripe wrasse and bird wrasse and then bird wrasse and sixbar wrasse (Fig. 2).

\section{Expectations of spatial covariance among competing wrasses}

We observed 127 fish (all either bird wrasse, sixbar wrasse or fivestripe wrasse) on 55 of the 96 reefs surveyed. Although a trend of negative spatial covariation in the density of bird and fivestripe wrasse occurred, this was non-significant $\left(\mathrm{n}=36 ; F_{1,34}=\right.$ 1.8514; $\mathrm{p}=0.1826$; density of bird wrasse $=0.126 x-$ $0.177 ; R^{2}=0.052$ ). As the contact matrix identified a competitive hierarchy, with a simple linear sequence of competitive ability, we hypothesized that the density of the inferior competitor (sixbar wrasse) would be negatively correlated with the density of the superior competitors (bird wrasse and fivestripe wrasse). We therefore pooled the density of bird and fivestripe wrasse and evaluated their combined influence on the density of sixbar wrasse, the inferior competitor. The density of sixbar wrasse and competitors (bird and fivestripe wrasse, pooled) ranged between 0 and 0.71 and between 0 and 0.74 ind. $\mathrm{m}^{-2}$, respectively. Correlations between the density of sixbar wrasse and competitors were equally well explained by the negative exponential model $\left(\right.$ AIC $=-36.788 ; \mathrm{R}^{2}=$ $0.20 ; \mathrm{p}=0.014$ ) and the linear model (AIC $=-38.301$; $\mathrm{R}^{2}=0.177 ; \mathrm{p}=0.0014 ; \Delta$ AIC $\left.=1.513\right)$. Both models indicated reductions in the density of sixbar wrasse with increases in competitor density (Fig. 3).

\section{DISCUSSION}

Competitive interactions among reef fishes have historically been considered more or less symmetric. However, our findings demonstrate asymmetric competition and add to a growing body of evidence that asymmetric competitive interactions can influence the distribution and abundance of reef fishes (e.g. Schmitt \& Holbrook 1999, Munday et al. 2001, Mun-

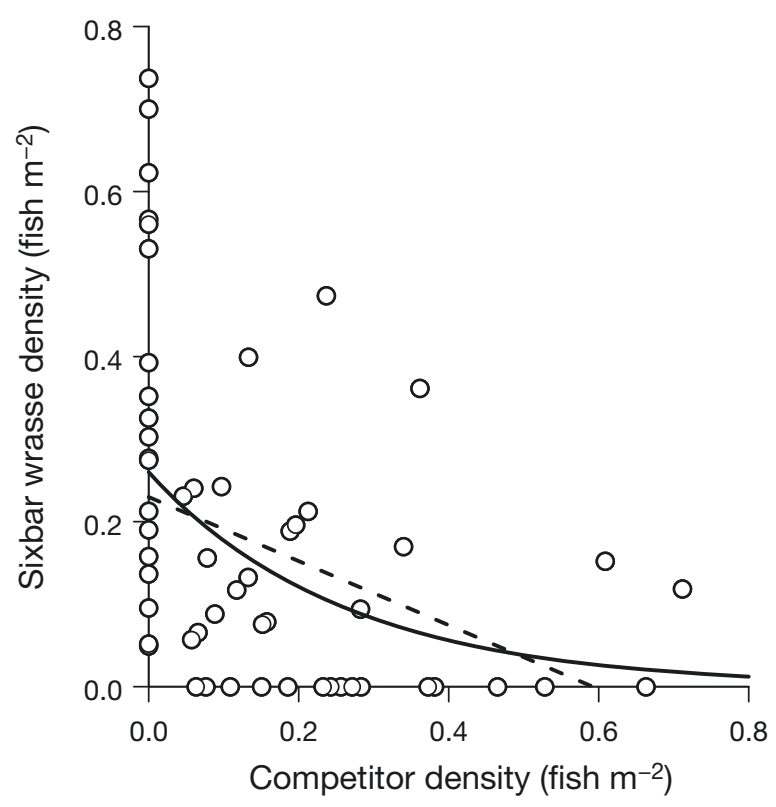

Fig. 3. Gomphosus varius, Thalassoma hardwicke, T. quinquevittatum. The relationship between the density of the sixbar wrasse and competitors on 55 patch reefs. Competitor density is the cumulative density of the bird wrasse and the fivestripe wrasse. Solid line: relationship as determined by a negative exponential model $\left(\mathrm{R}^{2}=0.20\right)$; dashed line: relationship as determined by a linear model (density of sixbar wrasse $\left.=0.230 x-0.388 ; R^{2}=0.177 ; p=0.001\right)$

day 2004). Furthermore, the present study is among the first to embed pairs of inferior and superior juvenile reef fish competitors within a suite of 3 competing species, and in doing this, our work identifies a simple linear competitive hierarchy.

Because the species examined here form mixed species groups following settlement, any one species will often come into contact with individuals of many different species, resulting in competitive interactions that will occur between a suite of species. Both the bird wrasse and the fivestripe wrasse were competitively superior to the sixbar wrasse. Furthermore, the fivestripe wrasse was competitively superior to the bird wrasse, resulting in a linear competitive hierarchy between these 3 species (fivestripe wrasse $>$ bird wrasse $>$ sixbar wrasse). The presence of a linear competitive hierarchy suggests that there will be a single competitive 'winner' capable of excluding all other species unless some other mechanism facilitates co-occurrence.

Density surveys of juveniles of our 3 focal species confirmed the hypothesis of negative spatial covariation in the abundance of superior and inferior competitors. As the rate of mortality in reef fishes typically declines with age or size (Schmitt \& Holbrook 1999, 
Steele \& Forrester 2002), patterns of spatial covariation established in early stages (as shown here) could persist through older stages. The abundance of superior competitors (bird wrasse and fivestripe wrasse) accounted for $\sim 20 \%$ of the spatial variability in the density of the inferior competitor (sixbar wrasse). The small amount of variation in the density of sixbar wrasse explained by the density of superior competitors could result from a number of processes. (1) Previous research examining competitive interactions between juvenile fivestripe wrasse and sixbar wrasse has demonstrated that the sequence (who arrives first) and timing (by how much) of arrival of fivestripe wrasse and sixbar wrasse on reefs can influence the magnitude (and in some instances direction) of asymmetric competition between these species (Geange \& Stier 2009). For example, when both species arrived on a reef simultaneously, sixbar wrasse were competitively inferior to fivestripe wrasse; however, fivestripe wrasse were competitively inferior when they arrived on a reef $12 \mathrm{~d}$ later than sixbar wrasse. Natural variability in the relative timing of arrival of the 3 species examined here may alter the relative competitive abilities of bird wrasse, fivestripe wrasse and sixbar wrasse and further explain why the density of superior competitors explained only a small (although statistically significant) proportion of the variability in the density of inferior competitors. (2) Although competition is predicted to be greatest among more closely related taxa (Dayan \& Simberloff 2005), competitive interactions can, in some instances, be strongest among more distant lineages (e.g. McClanahan 2000). For example, competition among juveniles of the 3 focal species in the present study commonly occurs for structurally complex branching corals (e.g. Pocillopora), which provide predator-free space. These corals are also used as predator-free space by large groups of damselfish. Some of the variability in the survey data may be explained by large numbers of damselfish (>45 ind. per small coral; Holbrook \& Schmitt 2002) saturating predator-free space, thereby competitively excluding wrasses and increasing their exposure to small-bodied resident piscivores. Similarly, spatial covariation in the availability of branching corals or predator density could also account for additional variability in the data. (3) Competition-colonization tradeoffs (Levins \& Culver 1971, Tilman 1994, Hurtt \& Pacala 1995) may swamp the negative effects of the sixbar wrasse being an inferior competitor. The settlement density of sixbar wrasse in the northern lagoon of Moorea is frequently 10 times greater than that of either the bird wrasse or the fivestripe wrasse (authors' pers. obs.).
The results of our experiment suggested that when density is held constant, per-capita survival of the superior competitor (fivestripe wrasse) was greater in the presence of heterospecifics than in the presence of conspecifics. Classic competition theory (Colwell \& Fuentes 1975, Diamond 1978) predicts that over evolutionary time, intraspecific competition should be stronger than interspecific competition because competitive exclusion and niche diversification will lead to resource partitioning among species. Interestingly, this was not true for the other 2 species examined. The per-capita effects of intraspecific competition for the bird wrasse was less than and equal to the interspecific competition with the fivestripe wrasse and the sixbar wrasse, respectively. For sixbar wrasse, the per-capita effects of intraspecific competition were weaker than the per-capita effects of interspecific competition with both the bird wrasse and the fivestripe wrasse. This suggests that the relative strength of inter- and intraspecific competition will depend upon the identity of the competing species, and that coexistence is maintained by some mechanism other than niche differentiation.

In conclusion, the present study demonstrates that when bird wrasse, fivestripe wrasse and sixbar wrasse arrive simultaneously onto patch reefs in high densities, intense asymmetric competition between species pairs results. When pairs of inferior and superior competitors are placed in 3-species suites of competitors, linear competitive hierarchies ensue, and these appear to be an important determinant of resource monopolization and patterns of distribution and abundance. The presence of linear competitive hierarchies suggests that, given sufficient time, the best competitor will drive all others locally extinct unless some other mechanism facilitates coexistence. Given our knowledge of this system, we hypothesize that competition-colonization tradeoffs maintain the coexistence of these 3 species, whereby high settlement of the inferior competitor swamps the negative effects of superior competitors.

Acknowledgements. T. Jones provided valuable comments on earlier versions of this manuscript. Staff of the Richard B. Gump South Pacific Research Station provided logistical support. This project was possible with financial support from NSF (OCE-0242312), Fulbright-Ministry of Research, Science and Technology Graduate Student Award, New Zealand Post Graduate Study Abroad, Three Seas and French American Cultural Exchange Fellowship and National Geographic International Ecostations. The present study is a contribution from UC Berkeley's Richard B. Gump South Pacific Research Station, Moorea, French Polynesia. 


\section{LITERATURE CITED}

Allesina S, Levine JM (2011) A competitive network theory of species diversity. Proc Natl Acad Sci USA 108:5638-5642

> Almany GR (2003) Priority effects in coral reef fish communities. Ecology 84:1920-1935

> Anderson GRV, Ehrlich AH, Ehrlich PR, Roughgarden JD, Russell BC, Talbot FH (1981) The community structure of coral reef fishes. Am Nat 117:476-495

$>$ Atkinson WD, Shorrocks B (1981) Competition on a divided and ephemeral resource: a simulation model. J Anim Ecol 50:461-471

- Beukers JS, Jones GP, Buckley RM (1995) Use of implant microtags for studies on populations of small reef fish. Mar Ecol Prog Ser 125:61-66

Blower SM, Mclean AR (1991) Mixing ecology and epidemiology. Proc Biol Sci 245:187-192

Burnham KP, Anderson DR (1998) Model selection and inference. Springer-Verlag, New York, NY

> Buss LW, Jackson JBC (1979) Competitive networks: nontransitive competitive relationships in cryptic coral reef environments. Am Nat 113:223-234

> Caselle JE (1999) Early post-settlement mortality in a coral reef fish and its effect on local population size. Ecol Monogr 69:177-194

Chesson P (1994) Multispecies competition in variable environments. Theor Popul Biol 45:227-276

> Chesson P (2000) Mechanisms of maintenance of species diversity. Annu Rev Ecol Syst 31:343-366

> Chesson P, Warner R (1981) Environmental variability promotes coexistence in lottery competitive systems. Am Nat 117:923-943

> Colwell RK, Fuentes ER (1975) Experimental studies of the niche. Annu Rev Ecol Syst 6:281-310

> Connell JH (1961) The influence of interspecific competition and other factors on the distribution of the barnacle Chthamalus stellatus. Ecology 42:710-723

> Connell JH (1978) Diversity in tropical rain forests and coral reefs. Science 199:1302-1310

$>$ Connell JH (1983) On the prevalence and relative importance of interspecific competition: evidence from field experiments. Am Nat 122:661-696

Dayan T, Simberloff D (2005) Ecological and communitywide character displacement: the next generation. Ecol Lett 8:875-894

Diamond JM (1978) Niche shifts and the rediscovery of interspecific competition. Am Sci 66:322-333

Ebersole JP (1985) Niche separation of two damselfish species by aggression and differential microhabitat utilization. Ecology 66:14-20

Frederick JL (1997) Evaluation of fluorescent elastomer injection as a method for marking small fish. Bull Mar Sci 61:399-408

Galzin R (1987) Structure of fish communities of French Polynesian coral reefs. I. Spatial scales. Mar Ecol Prog Ser 41:129-136

Galzin R, Pointer JP (1985) Moorea Island, Society Archipelago. In: Delesalle B, Galzin R, Salvat B (eds) 5th Int Coral Reef Congr, Tahiti 1:73-102

> Geange SW (2010) Effects of larger heterospecifics and structural refuge on the survival of a coral reef fish, Thalassoma hardwicke. Mar Ecol Prog Ser 407:197-207

$>$ Geange SW, Stier AC (2009) Order of arrival affects competition in two reef fishes. Ecology 90:2868-2878

Geange SW, Stier AC (2010) Priority effects and habitat complexity affect the strength of competition. Oecologia 163:111-118

Gladfelter WB, Ogden JC, Gladfelter EH (1980) Similarity and diversity among coral reef fish communities: a comparison between tropical western Atlantic (Virgin Islands) and tropical central Pacific (Marshall Islands) patch reefs. Ecology 61:1156-1168

Gotelli NJ, Ulrich W, Maestre FT (2011) Randomization tests for quantifying species importance to ecosystem function. Methods Ecol Evol 2:634-642

Hanski I (1981) Coexistence of competitors in patchy environment with and without predation. Oikos 37:306-312

Hardin G (1960) The competitive exclusion principle. Science 131:1292-1297

> Hixon MA (1980) Competitive interactions between California reef fishes of the genus Embiotoca. Ecology 61: 918-931

Holbrook SJ, Schmitt RJ (1995) Compensation in resource use by foragers released from interspecific competition. J Exp Mar Biol Ecol 185:219-233

Holbrook SJ, Schmitt RJ (2002) Competition for shelter space causes density-dependent predation mortality in damselfishes. Ecology 83:2855-2868

Huisman J, Johansson AM, Folmer EO, Weissing FJ (2001) Towards a solution of the plankton paradox: the importance of physiology and life history. Ecol Lett 4:408-411

> Hurtt GC, Pacala SW (1995) The consequences of recruitment limitation: reconciling chance, history and competitive differences between plants. J Theor Biol 176:1-12

> Huston M (1979) A general hypothesis of species diversity. Am Nat 113:81-101

> Imbert H, Beaulaton L, Rigaud C, Elie P (2007) Evaluation of visible implant elastomer as a method for tagging small European eels. J Fish Biol 71:1546-1554

Laird RA, Schamp BS (2006) Competitive intransitivity promotes species coexistence. Am Nat 168:182-193

> Larson RJ (1980) Competition, habitat selection, and the bathymetric segregation of two rockfish (Sebastes) species. Ecol Monogr 50:221-239

> Levine J (1999) Indirect facilitation: evidence and predictions from a riparian community. Ecology 80:1762-1769

> Levins R, Culver D (1971) Regional coexistence of species and competition between rare species. Proc Natl Acad Sci USA 68:1246-1248

> McClanahan TR (2000) Recovery of a coral reef keystone predator, Balistapus undulatus, in East African marine parks. Biol Conserv 94:191-198

Munday PL (2004) Competitive coexistence of coraldwelling fishes: the lottery hypothesis revisited. Ecology 85:623-628

Munday P, Jones G, Caley M (2001) Interspecific competition and coexistence in a guild of coral-dwelling fishes. Ecology 82:2177-2189

Myers RF (1999) Micronesian reef fishes: a field guide for divers and aquarists. Coral Graphics, Guam

R Development Core Team (2010) R: a language and environment for statistical computing. R Foundation for Statistical Computing, Vienna. www.r-project.org

Randall JE (2005) Reef and shore fishes of the South Pacific: New Caledonia to Tahiti and the Pitcairn Islands. University of Hawaii Press, Honolulu, HI

> Reichenbach T, Mobilia M, Frey E (2007) Mobility promotes and jeopardizes biodiversity in rock-paper-scissors games. Nature 448:1046-1049

Robertson DR (1996) Interspecific competition controls 
abundance and habitat use of territorial Caribbean damselfishes. Ecology 77:885-899

Robertson DR, Gaines SD (1986) Interference competition structures habitat use in a local assemblage of coral reef surgeonfishes. Ecology 67:1372-1383

Sale PF (1974) Mechanisms of co-existence in a guild of territorial fishes at Heron Island. Proc 2nd Int Coral Reef Symp 1:192-206

Sale PF (1976) Reef fish lottery. Nat Hist 85:60-65

Sale PF (1977) Maintenance of high diversity in coral reef fish communities. Am Nat 111:337-359

Sale PF (1978) Coexistence of coral reef fishes - a lottery for living space. Environ Biol Fishes 3:85-102

Sale PF (1980) Assemblages of fish on patch reefs - predictable or unpredictable? Environ Biol Fishes 5:243-249

Schmitt R, Holbrook S (1990) Mortality of juvenile damselfish: implications for assessing processes that determine abundance. Ecology 80:35-50

Schmitt RJ, Holbrook SJ (1999) Settlement and recruitment of three damselfish species: larval delivery and competition for shelter space. Oecologia 118:76-86

Schoener T (1983) Field experiments on interspecific competition. Am Nat 122:240-285

Shima JS (2001) Regulation of local populations of a coral

Editorial responsibility: Tim McClanahan,

Mombasa, Kenya reef fish via joint effects of density- and number-dependent mortality. Oecologia 126:58-65

Shima JS, Osenberg CW, St. Mary CM (2008) Quantifying site quality in a heterogeneous landscape: recruitment of a reef fish. Ecology 89:86-94

Simon J (2007) Evaluation of marking European silver eels with visible implant elastomer tags and alcian blue. J Fish Biol 70:303-309

Steele MA, Forrester GE (2002) Early postsettlement predation on three reef fishes: effects on spatial patterns of recruitment. Ecology 83:1076-1091

Talbot FH, Russell BC, Anderson GRV (1978) Coral reef fish communities: unstable, high-diversity systems? Ecol Monogr 48:425-440

Tilman D (1982) Resource competition and community structure. Princeton University Press, Princeton, NJ

> Tilman D (1994) Competition and biodiversity in spatially structured habitats. Ecology 75:2-16

Victor BC (1986) Duration of the planktonic larval stage of one hundred species of Pacific and Atlantic wrasses (family Labridae). Mar Biol 90:317-326

> Young KA (2004) Asymmetric competition, habitat selection, and niche overlap in juvenile salmonids. Ecology 85: 134-149

Submitted: May 21, 2012; Accepted: August 21, 2012

Proofs received from author(s): November 26, 2012 